\title{
Development and evaluation of an
} efficient heterologous gene knock-in reporter system in Lactococcus lactis

\author{
Yifei Lu, Hongxiang Yan, Jiezhong Deng, Zhigang Huang, Xurui Jin, Yanlan Yu, Qiwen Hu, Fuquan Hu \\ and Jing Wang ${ }^{*}$ (D)
}

\begin{abstract}
Background: Lactococcus lactis is a food grade probiotics and widely used to express heterologous proteins. Generally, target genes are knocked into the L. lactis genome through double-crossover recombination to express heterologous proteins stably. However, creating marker-less heterologous genes knocked-in clones is laborious. In this study, an efficient heterologous gene knock-in reporter system was developed in L. lactis NZ9000.
\end{abstract}

Results: Our knock-in reporter system consists of a temperature-sensitive plasmid pJW and a recombinant L. lactis strain named NZB. The pJW contains homologous arms, and was constructed to knock-in heterologous genes at a fixed locus of NZ9000 genome. lacZ ( $\beta$-galactosidase) gene was knocked into the chromosome of NZ9000 as a counter-selective marker through the plasmid pJW to generate NZB. The engineered NZB strain formed blue colonies on X-Gal plate. The desired double-crossover mutants formed white colonies distinctive from the predominantly blue colonies (parental and plasmid-integrated clones) when the embedded lac $Z$ was replaced with the target heterologous genes carried by pJW in NZB.

Conclusions: By using the system, the heterologous gene knocked-in clones are screened by colony phenotype change rather than by checking colonies individually. Our new knock-in reporter system provides an efficient method to create heterologous genes knocked-in clones.

Keywords: Lactococcus lactis, NZ9000, Knocked-in heterologous gene, Knock-in reporter system, lacZ

\section{Background}

Lactococcus lactis, a food-grade Gram-positive lactic acid bacterium, is commonly used to manufacture fermented dairy products, such as (soft) cheese, buttermilk, and sour cream [1, 2]. Since 1980s, extensive research on $L$. lactis has revealed considerable information on the biological, genetic, and immunological characteristics of this species [3, 4]. L. lactis has been broadly used as an "efficient cell factory" for recombinant protein production [5] because of the following properties: (i) As a generally regarded as safe (GRAS) microorganism [1], L. lactis elicits weak immune responses against itself and does

*Correspondence: wangjing2008@aliyun.com

Department of Microbiology, Third Military Medical University, Chongqing 400038, China not colonize the gut of humans and animals [6]. Thus, $L$. lactis can be directly used in the digestive tract $[7,8]$. (ii) L. lactis is genetically easy to manipulate, because of its completely sequenced genome [9-11] and many available genetic tools $[3,5,12]$. (iii) The downstream purification processes of secreted recombinant proteins are simple because $L$. lactis secretes only one major protein, namely, Usp45 [5]. Several kinds of heterologous proteins, such as enzymes [13-15], therapeutic proteins [16-18], growth factors [19-21], and antigens [3, 6, 12, 22], have been expressed in L. lactis. Therefore, L. lactis is a suitable host for heterologous gene expression and becomes the focus of food industry, biopharmaceuticals, and vaccine research.

Heterologous proteins can be expressed in $L$. lactis by encoding their genes harbored in vectors, such as 
pNZ8148 [3, 23], pMG36e [15, 24], pAMJ399 [19-21], and pLEB590 $[25,26]$. However, this approach is limited by several disadvantages. (i) In these vectors, antibioticresistant genes, which are banned for use in humans, are commonly employed as selective markers. (ii) Food-grade selective markers, such as nisin resistance gene (nsr), have been applied in L. lactis. However, most of the foodgrade selective markers cannot be used in Escherichia coli. Therefore, plasmids containing these food-grade selective markers can only be constructed in L. lactis, but the efficiency of constructing plasmids in L. lactis is much lower than that in E. coli. (iii) Plasmids in L. lactis are unstable in human and animal digestive tracts in the abundance of selective pressure. As an efficient alternative approach, the knock-in of target genes into L. lactis chromosome through double-crossover recombination is performed to stably express heterologous proteins without antibiotic-selective markers.

Temperature-sensitive (Ts) plasmids are usually utilized to integrate heterologous genes into the L. lactis genome. The entire process is accomplished in two steps [27]. First, a Ts plasmid harboring a target heterologous gene is transformed into L. lactis. Single-crossover recombinants are then obtained by culturing the transformants with antibiotics at a nonpermissive temperature. Second, plasmid-integrated clones are grown at a permissive temperature in an antibiotic-free medium. The integrated vector can be excised from the genome at a low frequency through a second recombination and consequently produce wild-type or heterologous gene knocked-in (HGK) strain without antibiotic resistance. To screen non-resistant clones, we individually examine the antibiotic resistance provided by integrated plasmids in colonies. HGK clones are subsequently checked through PCR. However, screening is laborious and time consuming, that is, this process requires several days to weeks. Therefore, a rapid screening method for HGK clones is desirable.

In this study, a heterologous gene knock-in reporter system was established for $L$. lactis NZ9000 ( $\beta$-galactosidase negative strain) through visual selection. The proposed system comprised a Ts $\mathrm{pJW}$ plasmid and a recombinant L. lactis NZB strain. pJW contains homologous arms, and was constructed to knock-in heterologous genes at a fixed locus of NZ9000 genome. Afterward, the lacZ ( $\beta$-galactosidase) gene was knocked-in the chromosome of NZ9000 by pJW. The resulting mutant strain, named NZB, formed blue colonies on X-Gal (5-bromo-4-chloro3 -indolyl- $\beta$-D-galactopyranoside) plate. To knock a target gene into L. lactis chromosome through the knock-in reporter system, the heterologous gene was firstly inserted in $\mathrm{pJW}$. Then, the $\mathrm{pJW}$ vector harboring the target gene was transformed into NZB. When the heterologous gene was knocked into the NZB chromosome and replaced the
lacZ gene by double-crossover recombination, the HGK clones formed white colonies on X-Gal plate and were distinguished from the other blue colonies. The HGK clones were then screened by selecting the white colonies from blue colonies rather than by checking colonies individually. By utilizing our knock-in reporter system, the HGK clones were produced simply and efficiently.

\section{Results}

\section{Construction of the Ts plasmid pJW}

$\mathrm{pJW}$, a Ts vector, was constructed and used in subsequent experiments. This vector was based on pUC18 added with a Ts replication origin $\operatorname{RepA}(\mathrm{Ts})[27,28]$, an erythromycin resistance gene from pCrePA2 $[29,30]$, and a unified homologous sequence with an $A s c$ I restriction site at the center (Fig. 1). The homologous sequence was an internal $2.5 \mathrm{~kb}$-fragment of the histidine operon of $L$. lactis NZ9000 (His locus) [31] and used for recombination. The heterologous genes were inserted into the AscI site by restriction digestion and ligation, and the fragment was divided into two parts (Hisa and Hisb). These two parts then served as homologous arms for recombination in L. lactis [32]. If the AscI restriction site is present in the gene of interest, the gene can be inserted into the $A s c \mathrm{I}$ site by a seamless cloning strategy. $\mathrm{pJW}$ contains ampicillin- and erythromycin-resistant genes.

\section{Construction of NZB strain}

We first integrated a lacZ gene with a promoter into the His locus of the chromosome of NZ9000 because $\beta$-galactosidase gene is absent in the NZ9000 chromosome.

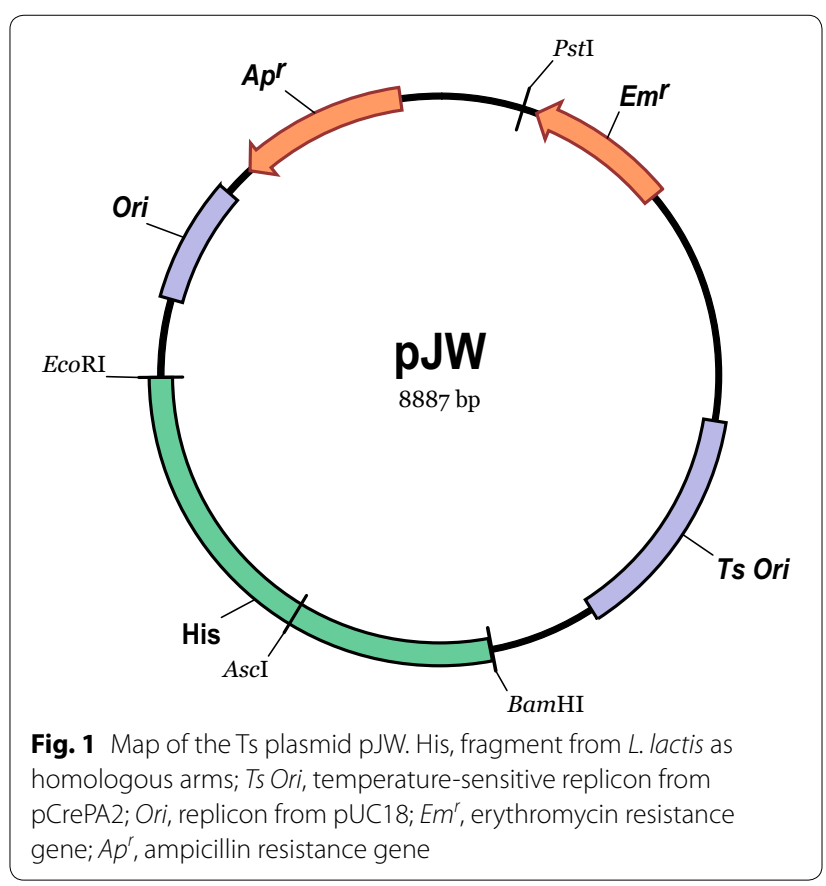


The PZLT fragment containing a nisin promoter $P_{\text {nis }}$ from L. lactis N8 [33], lacZ from Lactobacillus acidophilus [34], and a terminator from the pMG36e plasmid $[15,35]$ was cloned into pJW to create pJW-PZLT (Additional file 1: Figure S2). $P_{\text {nisZ }}$, which can be induced in the presence of nisin in NZ9000, was artificially synthesized on the basis of the reference sequence [33].

The PZLT expression cassette was knocked into NZ9000 chromosome by pJW-PZLT plasmid. The blue colonies were screened separately by erythromycin-resistance test. Erythromycin-sensitive colonies represent the strains with plasmid region excised by double-crossover event and eliminated by culturing at $37^{\circ} \mathrm{C}$. The erythromycin-sensitive blue colonies were then checked by multiple-PCR analysis (Fig. 2a), and all PCR products (Fig. 2b) corresponded to the theoretical sizes (Additional file 1: Table S1). Subsequent sequencing of PCR products amplified with primers pairs specific to the genomic regions flanked by the homologous arms (LO$\mathrm{RO})$ confirmed that the PZLT fragment was knocked into the $L$. lactis genome. The engineered strain was named NZB which formed blue colonies on the M17GS-XN plate (Fig. 2c).
Evaluating the efficiency of heterologous gene knock-in reporter system in L. lactis

The "efficient heterologous gene knock-in reporter system in L. lactis" is composed of the pJW plasmid and the NZB strain. To integrate a heterologous gene into the NZB chromosome, we used the built-in lacZ gene as a target counter-selection marker. The NZB strain loses its ability to produce $\beta$-galactosidase and forms white colonies that are easily distinguished from the blue parental colonies on an X-Gal plate when the built-in lacZ gene is replaced by the gene of interest via double-crossover recombination.

To evaluate the feasibility and efficiency of the knockin reporter system, five heterologous DNA fragments (HDFs) varied from $\sim 1.3$ to $\sim 14.6 \mathrm{~kb}$ were integrated into the chromosome of $L$. lactis NZB by using the knock-in reporter system. The five HDFs of interest were inserted in the AscI site of pJW by seamless cloning, creating pJW-1.3, pJW-2.2, pJW-3.8, pJW-7.3, and pJW-14.6, respectively. After the HDF-containing plasmids were integrated into NZBs chromosome (Fig. 3b), the plasmid-integrated clones were then grown in the M17GS medium without antibiotic overnight at $25{ }^{\circ} \mathrm{C}$ (Fig. 3c),
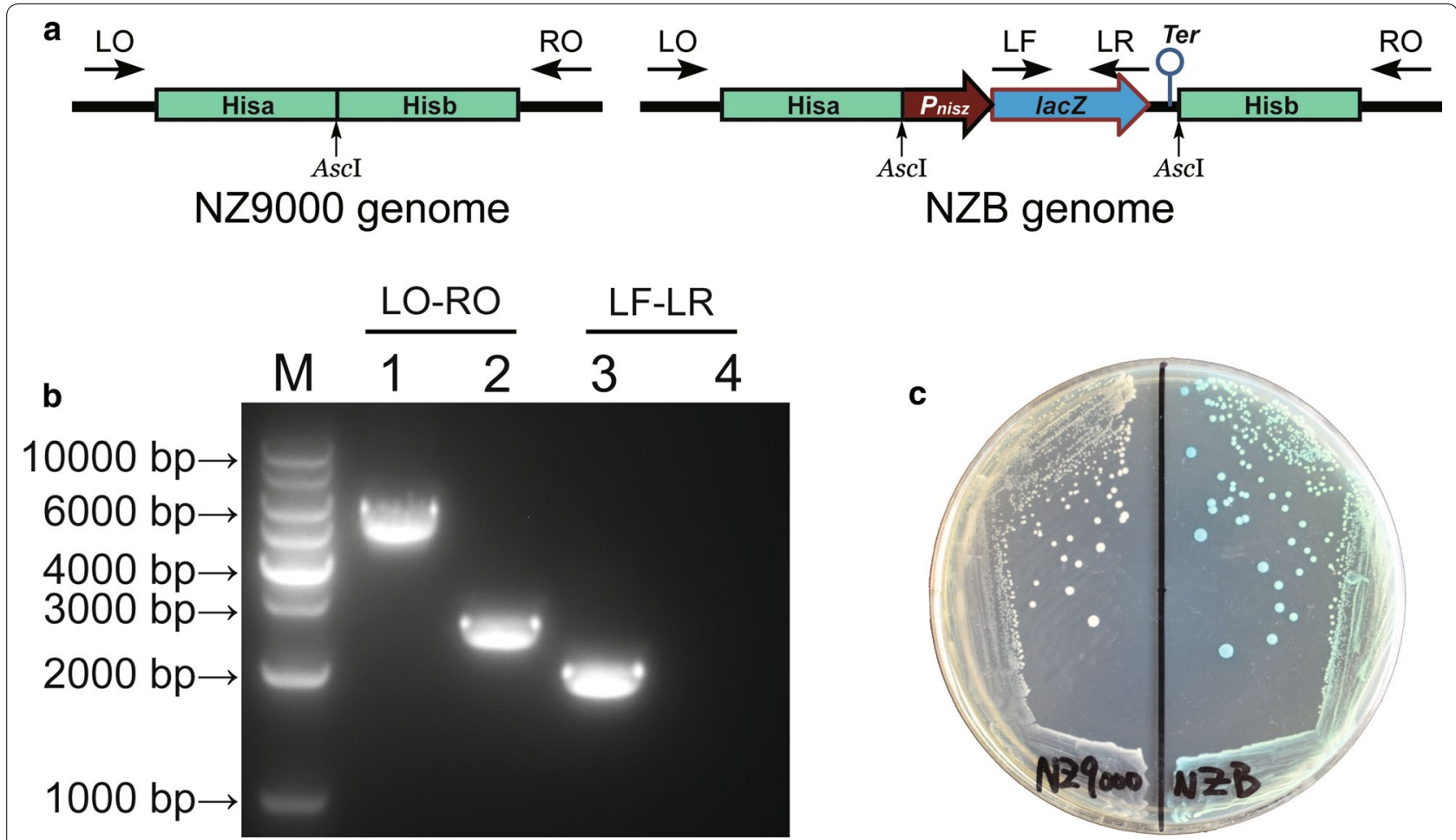

Fig. 2 Confirmation analysis of the NZB strain. a Schematic of genomes of NZ9000 and NZB. LO, RO, LF, LR, primers used in multiple-PCR analysis. b Multiple-PCR analysis of the NZB and NZ9000 strain. The primer combinations used in PCR are presented on the lanes. Genomic DNA from the following strains were used as templates: NZB (lanes 1 and 3) and NZ9000 (lanes 2 and 4). The 1 kb DNA ladder marker is shown on the left (M). The theoretical size (bp) of each PCR products generated with the primer combinations is shown in Additional file 1: Table S1. c NZ9000 (left) and NZB (right) colonies on M17GS-XN 


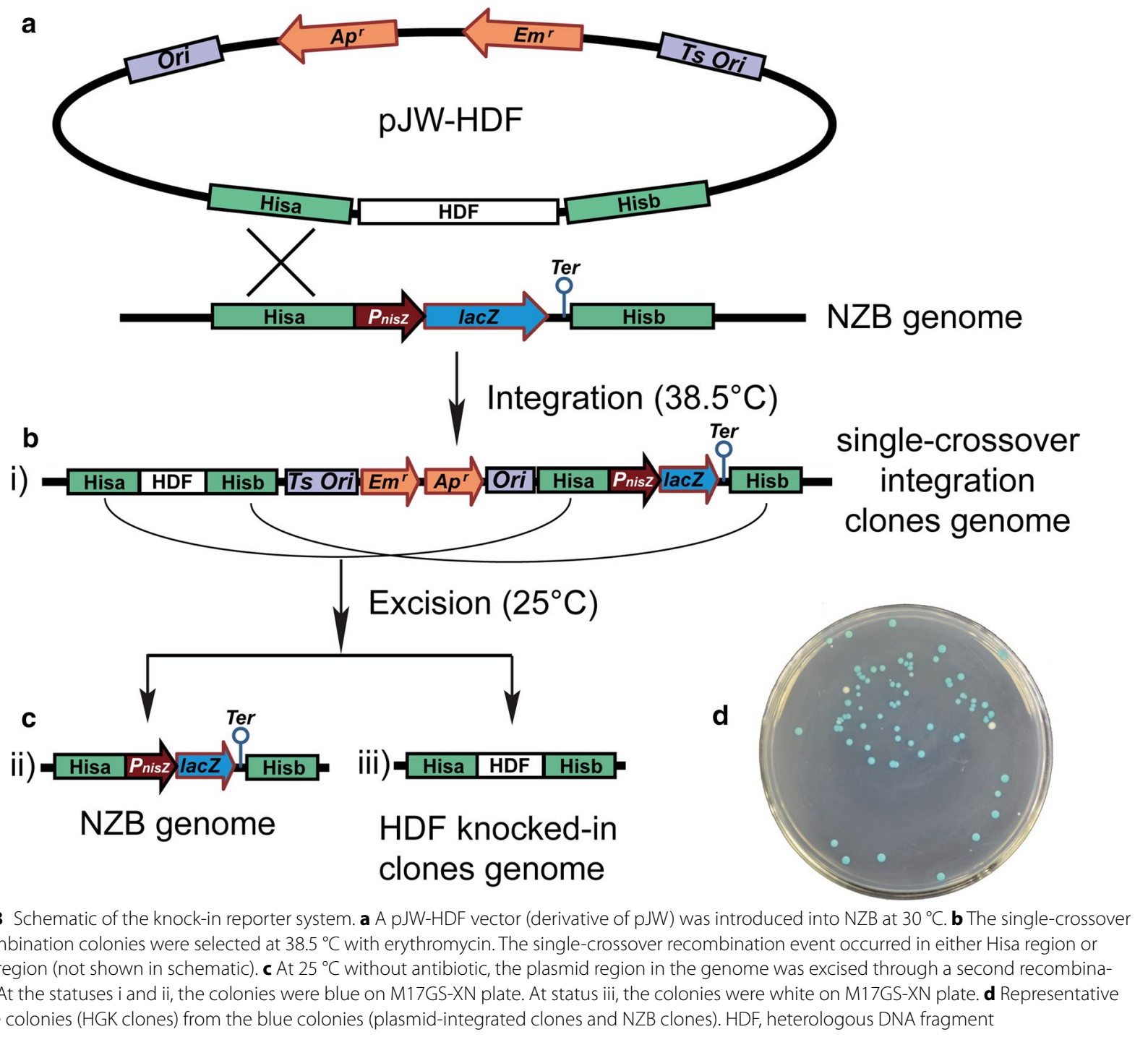

and plated on M17GS-XN at $37{ }^{\circ} \mathrm{C}$ until most colonies turned blue. Colonies were formed on the plates from the following three cases. The second recombination did not occur produced plasmid-integrated clones (i); the plasmids were excised via a second allelic exchange and resulted in parental clones NZB (ii), or HGK clones (iii) (Fig. 3b, c). For (i) and (ii), the clones contained the lac $Z$ gene, and the colonies were blue on M17GS-XN agar. Only in (iii), were the lacZ gene replaced by HDFs, and the resultant colonies (HGK clones) were white on M17GS-XN agar (Fig. 3d).

These white colonies were then verified by multiple assays. First, all the white colonies were sensitive to erythromycin; hence, the erythromycin-resistant integrated plasmids were excised and lost. Second, the white colonies were verified by multiple-PCR analysis (Fig. 4a), and all PCR products (Fig. 4b) corresponded to the theoretical sizes (Additional file 1: Table S1). Subsequent sequencing of the PCR products amplified with primers pairs specific to the genomic regions flanked by the homologous arms (LO-RO) confirmed that the HDFs were knocked into the NZB genomes and replaced the lacZ gene. The HDFs were named $1.3 \mathrm{k}-\mathrm{NZ}, 2.2 \mathrm{k}-\mathrm{NZ}$, $3.8 \mathrm{k}-\mathrm{NZ}, 7.3 \mathrm{k}-\mathrm{NZ}$, and 14.6k-NZ. We counted the white colony occurrence rate and accuracy rate. Although the white colonies occurrence rate was extremely low $\left(10^{-3}\right.$ to $\left.10^{-5}\right)$, the accuracy rate was $100 \%$ as expected (Table 1).

In conclusion, our knock-in reporter system can effectively knock-in the HDFs ranging from 1.3 to $14.6 \mathrm{~kb}$ into the L. lactis chromosome. Furthermore, the white colonies were HGK colonies, and the accuracy rate was $100 \%$. 


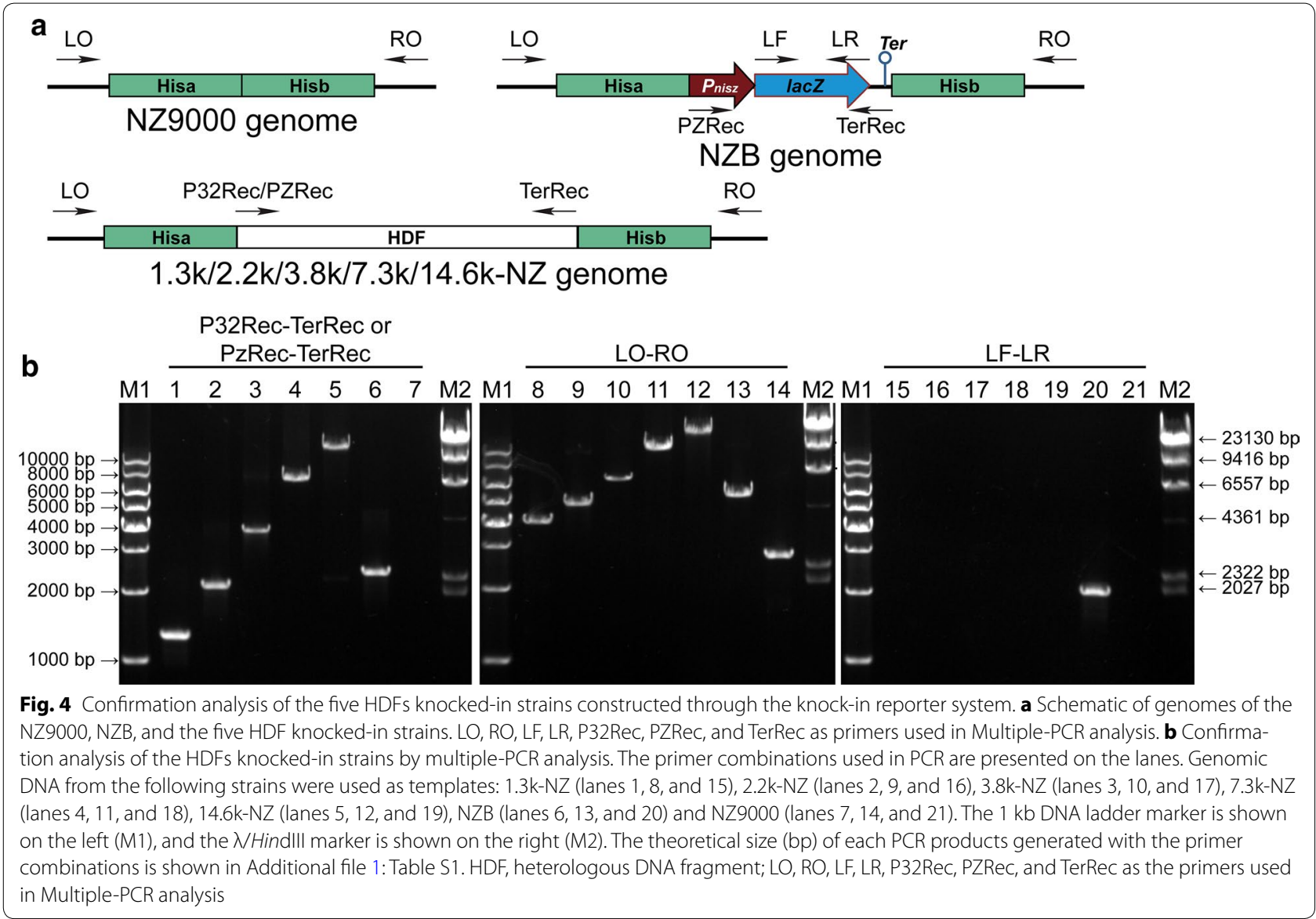

Table 1 White colony occurrence and accuracy rate in the evaluation of the knock-in reporter system

\begin{tabular}{lccccc}
\hline Name & HDF length (bp) & Total colonies & White colonies & White colony occurrence rate (\%o) & Accuracy rate (\%) \\
\hline $1.3 \mathrm{k}-\mathrm{NZ}$ & 1317 & 6765 & 58 & 8.873 & 100.00 \\
$2.2 \mathrm{k}-\mathrm{NZ}$ & 2163 & 7508 & 44 & 5.860 & 100.00 \\
$3.8 \mathrm{k}-\mathrm{NZ}$ & 3856 & 15,239 & 21 & 1.378 & 100.00 \\
$7.3 \mathrm{k}-\mathrm{NZ}$ & 7277 & 14,599 & 12 & 0.8220 & 100.00 \\
$14.6 \mathrm{k}-\mathrm{NZ}$ & 14,620 & 16,349 & 3 & 0.1835 & 100.00 \\
\hline
\end{tabular}

\section{Discussion}

In this work, we developed an efficient heterologous gene knock-in reporter system in L. lactis. The knock-in reporter system contains a Ts plasmid pJW and a NZB strain (a derivative of NZ9000). By using the knock-in reporter system, the HDF knocked-in NZB clones can be selected directly by colony phenotype (color) change (blue to white). Our assay largely reduced the required labor and time, and thus improved the efficiency of knock-in assay for L. lactis.

In the original assay, the knocked-in strains were screened by examining the loss of antibiotic resistance, hundreds and thousands of colonies must be examined individually to obtain antibiotic-sensitive clones. Some of these colonies were HDF knocked-in clones, and others were parental clones. In our assay, screening was simplified through visual observation of phenotypic colony changes, and the screening time was reduced from several weeks to several days.

The parental strain used in this study was NZ9000 $(L$. lactis subsp. cremoris) [11], a derivative of MG1363, and is the most commonly used host of the NIsin Controlled gene Expression (NICE) system. The NICE system is a highly successful and widely used tool for regulating of 
gene expression in $L$. lactis [11, 23, 36, 37]. When a gene of interest is placed at the downstream of the inducible promoter $P_{\text {nisA }}, P_{\text {nisF }}$, or $P_{\text {nisZ }}$ in NZ9000, industrial-scale gene expression can be induced by adding nisin (a foodgrade antimicrobial peptide produced by some strains of L. lactis) to the culture medium [36-38]. Besides nisin inducible promoters, other promoters, like constitutive promoters $P_{32}$ [39] and $P_{45}$ [33], and $\mathrm{pH}$ inducible promoter $P_{170}$ [40], can also work in NZ9000. Therefore, NZ9000 was chosen to develop the host strain of the knock-in reporter system instead of other L. lactis strains.

Two kinds of plasmids namely, non-replicative and Ts plasmids, are employed in gene knockout and knock-in. Non-replicative plasmids can be maintained by the target host only by specific recombination with the host genome, and the resulted clones are selected using antibiotics. Obtaining plasmid-integrated clones is difficult in certain hosts, such as L. lactis, because of low transformation efficiency. Owing to its large size, Ts plasmids are difficult to use in transforming target hosts. However, this kind of plasmids can be replicated in the target host at a permissive temperature. Transformants are easily achieved, and only one transformant is needed for subsequent operations. Therefore, we chose Ts plasmid as a vehicle of the gene of interest in our knock-in reporter system.

In the present study, the His locus, corresponding to a nonessential gene involved in histidine biosynthesis in L. lactis [31], was employed as the integration site, which was also described in a previous study by SimõesBarbosa et al. [32]. Their results demonstrated that the disruption of the His locus did not significantly affect growth of the heterologous gene integrated strain [32], which was confirmed by our results. Besides the His locus, thy $A$, a thymidylate synthase-encoding gene, was also used as integration site for the construction of delivery system in vivo $[17,41]$. Replacement of thy $A$ by heterologous genes creates thy $A$-deficient strains, which are self-limited and die rapidly in the absence of thymidine or thymine. Thus, the thyA-deficient bacteria can survive in vivo, but cannot accumulate in the environment [17].

This system can be only applied in $\beta$-galactosidase negative and nisRK-positive strains, such as NZ9000, because the nisin inducible promoter $P_{n i s Z}$ can only work in nisRK-positive strains. However, we believe that, the strategy can also be applied in other hosts. For $\beta$-galactosidase and nisRK genes negative strains, the nisin inducible promoter $P_{\text {nis } Z}$ in lacZ expression cassette should be replaced by constitutive promoters or other kind of inducible promoters (depend on host strains) [3]. For $\beta$-galactosidase positive strains, the $\beta$-galactosidase gene should be used as counter-selective marker.

\section{Conclusion}

In conclusion, the "efficient heterologous gene knock-in reporter system in L. lactis" is a convenient and practical tool to knock heterologous genes into L. lactis NZB strain (a derivative of NZ9000) efficiently, and enhances downstream research works.

\section{Methods}

Bacteria, plasmids, and culture conditions

All the bacteria strains and plasmids used in this study are listed in Table 2 and Additional file 1: Table S2. E. coli strain DH5 $\alpha$ was used as cloning host and cultured in Luria-Bertani (LB, Oxoid, UK) medium at $37^{\circ} \mathrm{C}$. L. lactis was cultured in M17GS (M17 [Oxoid, UK] supplemented with $0.5 \%$ [wt $/ \mathrm{vol}$.] glucose, $0.5 \%$ [wt $/ \mathrm{vol}$.$] lactose, 0.55 \%$ [wt/vol.] sucrose $)$ medium at $30{ }^{\circ} \mathrm{C}$. Ampicillin $(100 \mu \mathrm{g} /$ $\mathrm{mL}$, Tiangen, China) was used for E. coli. Erythromycin $(20 \mu \mathrm{g} / \mathrm{mL}, \mathrm{BBI}, \mathrm{Canada})$ was used for L. lactis. X-Gal (BBI, Canada) and nisin (Sigma-Aldrich, USA) were utilized at 40 and $0.1 \mu \mathrm{g} / \mathrm{mL}$, respectively, for screening in agar.

\section{DNA manipulations and sequencing}

The construction of plasmid $\mathrm{pJW}$ was performed in E. coli. The PCR primers used in this study are listed in Table 3. PCR products were purified with the Wizard SV Gel and PCR Clean-Up System (Promega, USA). Plasmids were isolated with the Plasmid Mini Kit (Omega Bio-tek, USA). The restriction enzymes were FastDigest Restriction Enzymes (Thermo Scientific, USA). Genomes were isolated with the TIANamp Bacteria DNA Kit (Tiangen, China). PCR products and plasmids were sequenced by the Beijing Genomics Institute (China). Seamless cloning was performed with the NovoRec PCR One-Step Directed Cloning kit (Novoprotein, China). Molecular manipulation [42], preparation of competent cells [43], and electrotransformation [43] was performed as described previously.

\section{Construction of Ts plasmid pJW}

The His fragment (2472 bp), an internal sequence of the histidine operon, was amplified from the genome of NZ9000 by PCR using PrimerStar DNA polymerase (high-fidelity DNA polymerase, Takara, China) with primers HisF and HisR from NZ9000 genome. The His fragment was then digested with $E c o$ RI, and inserted in the $S m a \mathrm{I} / E c o$ RI sites of pUC18. The resulting vector was named pUC-H. The "Ts-replicon::Em" fragment amplified from pCrePA2 vector with primers TsF and TsR was digested and inserted in the BamHI/PstI sites of pUC$\mathrm{H}$. The constructed vector was named $\mathrm{pJW}$ (Additional file 1: Figure S1). 
Table 2 Bacterial strains and plasmids used in this study

\begin{tabular}{|c|c|c|}
\hline Strain & Characteristics & Source \\
\hline E. coli DH5a & Cloning host for maintaining recombinant plasmids & Lab collection \\
\hline L. lactis NZ9000 & Derivative of MG1363; pepN::nisRK & [37], Lab collection \\
\hline L. lactis NZB & Derivative of NZ9000; $P_{\text {nisz: }}:$ acZ::terminator & This study \\
\hline \multicolumn{3}{|l|}{ Plasmids } \\
\hline pUC18 & Cloning vector; $A p^{r}$ & Lab collection \\
\hline $\mathrm{pUC}-\mathrm{H}$ & Derivative of pUC18; containing His fragment from L. lactis & This study \\
\hline pCrePA2 & An improved version of the pCrePA [29] plasmid containing Ts replicon; $A p^{r}, E m^{r}$ & Kindly gifted by Stephen H. Leppla \\
\hline pJW & L. lactis integration vector; derivative of $\mathrm{pUC}-\mathrm{H}$; containing Ts replicon from $\mathrm{pCrePA} 2 ; \mathrm{Ap}^{r}, \mathrm{Em}^{r}$ & This study \\
\hline pMG36e & Wide-host-range vector; $E m^{r}$ & [15], Lab collection \\
\hline PQE31-LacZ & Derivative of the expression vector pQE31; containing lacZ from Lactobacillus acidophilus; $A p^{r}$ & [34], Lab collection \\
\hline pMG-PZL & derivative of pMG36e; containing $P_{\text {nisz }}:$ lacZ; template of $P_{\text {nisz }}:$ lacZ::terminator; $E m^{r}$ & This study \\
\hline pJW-PZLT & L. lactis integration vector; derivative of $\mathrm{pJW}$; containing $P_{\text {nisz }}:$ IacZ::terminator; $A p^{r}, E m^{r}$ & This study \\
\hline
\end{tabular}

$A p^{r}$ ampicillin resistant, $E m^{r}$ erythromycin resistant, $T s$ temperature-sensitive

Table 3 Primers used in this study

\begin{tabular}{|c|c|c|}
\hline Primers & Sequence $\left(5^{\prime}-3^{\prime}\right)$ & Restriction sites \\
\hline HisF & AAAGAATTCTAAAGTAATTTTCATCAATTTTTTCTAAGC & ECORI \\
\hline HisR & GTTTGGGAGTCGCCTTTGGCTC & - \\
\hline TsF & AAAGGATCCTGATCGTTAAATTTATACTGCAAT & $\mathrm{BamHI}$ \\
\hline TsR & AAACTGCAGTACCTAATAATTTATCTACATTCCC & Pstl \\
\hline PZF & AAAGAATTCAGTCTTATAACTATACTGACAATAG & EcoRl \\
\hline PZR & TGATAATTGTGTCATTTTGAGTGCCTCCTTATAAT & - \\
\hline LF & AAGGAGGCACTCAAAATGACACAATTATCACGTTT & - \\
\hline LR & AAATCTAGACTAATTTCTCAATACTTGAACAT & $X b a l$ \\
\hline P32Rec & AAGTCGCGTGGCGCGCCGGTCCTCGGGATATGATA & Ascl \\
\hline PZRec & AAGTCGCGTGGCGCGCCAGTCTTATAACTATACTGACAATAG & Ascl \\
\hline TerRec & GAAATGATAGGCGCGCCATAAGCAAAAGGCAGCTGAT & Ascl \\
\hline LO & GCTCCATGAATTTCCTAATTGATGC & - \\
\hline $\mathrm{RO}$ & GATGAAGCTTATATTGACTTTGGCG & - \\
\hline
\end{tabular}

Restriction enzyme cut sites are in bold

\section{Construction of NZB strain}

The nisin promoter $P_{\text {nis } Z}$ [33] was artificially synthesized as template, and was amplified with the primers PZF and PZR. The lacZ gene (from L. acidophilus) was amplified from pQE31-LacZ [34] with the primers LF and LR. $P_{\text {nis } Z}$ and $l a c Z$ gene were combined by overlap PCR. The PCR product was digested by EcoRI/XbaI and cloned into the same sites of pMG36e [15] to yield the plasmid pMGPZL. The PZLT fragment $\left(P_{\text {nisZ: }}\right.$ :lacZ::terminator $)$ was then amplified from pMG-PZL with primers PZRec and TerRec and inserted into the AscI site of pJW by seamless cloning (Additional file 1: Figure S2).

The vector pJW-PZLT was introduced into L. lactis NZ9000 by electroporation, and the transformants were selected at $30{ }^{\circ} \mathrm{C}$ on M17GS-NX (M17GS agar containing $\mathrm{X}-\mathrm{Gal}$ and nisin) medium containing erythromycin
(Additional file 1: Figure S3A). One blue colony was streaked onto the same medium and incubated at $30{ }^{\circ} \mathrm{C}$. In the next step, a blue colony was inoculated in M17GS broth with erythromycin and incubated at $30{ }^{\circ} \mathrm{C}$ for $8 \mathrm{~h}$ and then diluted 1000-fold in the same medium and grown at nonpermissive temperature $\left(38.5{ }^{\circ} \mathrm{C}\right)$ overnight to select the chromosomal-plasmid-integrated strain (Additional file 1: Figure S3B). Next, the cultures were then diluted $1: 10^{6}$ in M17GS medium without antibiotic and grown overnight at permissive temperature $\left(25^{\circ} \mathrm{C}\right)$ to stimulate a second recombination event [27], and the plasmid was excised from chromosome (Additional file 1: Figure S3C). Dilutions of the overnight cultures were plated on M17GS-XN and incubated at $37{ }^{\circ} \mathrm{C}$ to eliminate the excised Ts plasmid. Single blue colonies were screened by replica plating on M17GS-XN plates 
versus M17GS-XN plates containing erythromycin. The erythromycin-sensitive blue colonies represented the strains with a plasmid region excised in a double-crossover event and the PZLT fragment inserted in the NZ9000 genome. The resultant stain was named NZB (Additional file 1: Figure S3).

\section{Evaluating the efficient heterologous gene knock-in reporter system in L. lactis}

To evaluate the knock-in reporter system, we knocked five different lengths (1.3-14.6 kb) of DNA fragments into the L. lactis NZB genome as heterologous genes. The five fragments were amplified from the vectors of our laboratory's collection with the primer pair P32RecTerRec or PZRec-TerRec and cloned into the vector pJW through its $A s c$ I site by seamless cloning. The constructed vectors were named pJW-1.3, pJW-2.2, pJW-3.8, pJW-7.3, and pJW-14.6 (Additional file 1: Table S2.). The five vectors were transformed into NZB, and the transformants were selected at $30{ }^{\circ} \mathrm{C}$ on M17GS-NX medium containing erythromycin (Fig. 3a). The plasmids harboring NZB were inoculated in M17GS broth with erythromycin and incubated at $30{ }^{\circ} \mathrm{C}$ for $8 \mathrm{~h}$, and were then diluted at $1: 10^{3}$ in the same medium and incubated at $38.5^{\circ} \mathrm{C}$ to select plasmid-integrated clones (Fig. 3b). The overnight cultures were then diluted at $1: 10^{6}$ in M17GS medium without antibiotic and grown overnight at $25^{\circ} \mathrm{C}$ (Fig. 3c). The overnight cultures were diluted and plated on M17GS-XN at $37{ }^{\circ} \mathrm{C}$ until most colonies turned blue. The white colonies were picked for further identification.

\section{Additional file}

Additional file 1. Additional tables and figures.

\section{Authors' contributions}

YFL, HXY, JZD, ZGH, XRJ, YLY and QWH designed and carried out the experiments, analyzed the data and drafted the manuscript. FQH and JW contributed to editing and revising the manuscript. JW draft the basic idea and supervised the study. All authors read and approved the final manuscript.

\section{Acknowledgements \\ We would like to thank Prof. Stephen H. Leppla for kindly providing plasmid pCrePA2.}

\section{Competing interests}

The authors declare that they have no competing interests.

\section{Availability of data and materials}

All data generated or analyzed during this study are included in this manuscript.

\section{Funding}

This study was funded by National Natural Science Foundation of China (NSFC, Grant No. 31201341), and Third Military Medical University Youth Science Foundation (Grant No. 2010XQN06).

\section{Publisher's Note}

Springer Nature remains neutral with regard to jurisdictional claims in published maps and institutional affiliations.

Received: 19 June 2017 Accepted: 9 September 2017

Published online: 18 September 2017

\section{References}

1. Leroy F, Vuyst LD. Lactic acid bacteria as functional starter cultures for the food fermentation industry. Trends Food Sci Technol. 2004;15:67-78.

2. Laroute V, Tormo H, Couderc C, Mercierbonin M, Le BP, Cocaignbousquet $M$, Daveranmingot ML. From genome to phenotype: an integrative approach to evaluate the biodiversity of Lactococcus lactis. Microorganisms. 2017. doi:10.3390/microorganisms5020027.

3. Pontes DS, de Azevedo MS, Chatel JM, Langella P, Azevedo V, Miyoshi A. Lactococcus lactis as a live vector: heterologous protein production and DNA delivery systems. Protein Expr Purif. 2011;79:165-75.

4. Makarova K, Slesarev A, Wolf Y, Sorokin A, Mirkin B, Koonin E, Pavlov A, Pavlova N, Karamychev V, Polouchine N, et al. Comparative genomics of the lactic acid bacteria. Proc Natl Acad Sci USA. 2006;103:15611-6.

5. Morello E, Bermudez-Humaran LG, Llull D, Sole V, Miraglio N, Langella P, Poquet I. Lactococcus lactis, an efficient cell factory for recombinant protein production and secretion. J Mol Microbiol Biotechnol. 2008;14:48-58.

6. Bahey-El-Din M. Lactococcus lactis-based vaccines from laboratory bench to human use: an overview. Vaccine. 2012;30:685-90.

7. Pochart Marteau. Pharmacokinetics of Lactobacillus plantarum NCIMB 8826, Lactobacillus fermentum KLD, and Lactococcus lactis MG 1363 in the human gastrointestinal tract. Aliment Pharmacol Ther. 2000;14:823-8.

8. Klijn N, Weerkamp AH, Vos WMD. Genetic marking of Lactococcus lactis shows its survival in the human gastrointestinal tract. Appl Environ Microbiol. 1995;61:2771-4.

9. Bolotin A, Wincker P, Mauger S, Jaillon O, Malarme K, Weissenbach J, Ehrlich SD, Sorokin A. The complete genome sequence of the lactic acid bacterium Lactococcus lactis ssp. lactis IL1403. Genome Res. 2001;11:731-53.

10. Siezen RJ, Bayjanov J, Renckens B, Wels M, van Hijum SA, Molenaar D, van Hylckama Vlieg JE. Complete genome sequence of Lactococcus lactis subsp. lactis KF147, a plant-associated lactic acid bacterium. J Bacteriol. 2010;192:2649-50.

11. Linares DM, Kok J, Poolman B. Genome sequences of Lactococcus lactis MG1363 (revised) and NZ9000 and comparative physiological studies. J Bacteriol. 2010;192:5806-12.

12. Gaspar P, Carvalho AL, Vinga S, Santos H, Neves AR. From physiology to systems metabolic engineering for the production of biochemicals by lactic acid bacteria. Biotechnol Adv. 2013;31:764.

13. Drouault S, Juste C, Marteau P, Renault P, Corthier G. Oral treatment with Lactococcus lactis expressing Staphylococcus hyicus lipase enhances lipid digestion in pigs with induced pancreatic insufficiency. Appl Environ Microbiol. 2002;68:3166-8.

14. Li J, Zhang W, Wang C, Yu Q, Dai R, Pei X. Lactococcus lactis expressing food-grade $\beta$-galactosidase alleviates lactose intolerance symptoms in post-weaning Balb/c mice. Appl Microbiol Biotechnol. 2012;96:1499-506.

15. van de Guchte M, van der Vossen JM, Kok J, Venema G. Construction of a lactococcal expression vector: expression of hen egg white lysozyme in Lactococcus lactis subsp. lactis. Appl Environ Microbiol. 1989;55:224-8.

16. Steidler $L$, Rottiers $P$. Therapeutic drug delivery by genetically modified Lactococcus lactis. Ann NY Acad Sci. 2006;1072:176-86.

17. Steidler L, Neirynck S, Huyghebaert N, Snoeck V, Vermeire A, Goddeeris B, Cox E, Remon JP, Remaut E. Biological containment of genetically modified Lactococcus lactis for intestinal delivery of human interleukin 10. Nat Biotechnol. 2003;21:785-9.

18. Wells JM, Mercenier A. Mucosal delivery of therapeutic and prophylactic molecules using lactic acid bacteria. Nat Rev Microbiol. 2008;6:349-62.

19. Huynh E, Li J. Generation of Lactococcus lactis capable of coexpressing epidermal growth factor and trefoil factor to enhance in vitro wound healing. Appl Microbiol Biotechnol. 2015;99:4667-77. 
20. Bedford A, Huynh E, Fu M, Zhu C, Wey D, de Lange C, Li J. Growth performance of early-weaned pigs is enhanced by feeding epidermal growth factor-expressing Lactococcus lactis fermentation product. J Biotechnol. 2014; 173:47-52.

21. Cheung QC, Yuan Z, Dyce PW, Wu D, Delange K, Li J. Generation of epidermal growth factor-expressing Lactococcus lactis and its enhancement on intestinal development and growth of early-weaned mice. Am J Clin Nutr. 2009;89:871-9.

22. Wyszyńska A, Kobierecka P, Bardowski J, Jagusztynkrynicka EK. Lactic acid bacteria-20 years exploring their potential as live vectors for mucosal vaccination. Appl Microbiol Biotechnol. 2015;99:2967-77.

23. Mierau I, Kleerebezem M. 10 years of the nisin-controlled gene expression system (NICE) in Lactococcus lactis. Appl Microbiol Biotechnol. 2005;68:705-17.

24. Zhang W, Wang C, Huang C, Yu Q, Liu H, Zhang C, Pei X. Construction and expression of food-grade $\beta$-Galactosidase gene in Lactococcus lactis. Curr Microbiol. 2010;62:639-44.

25. Liu G, Wang H, Griffiths MW, Li P. Heterologous extracellular production of enterocin P in Lactococcus lactis by a food-grade expression system. Eur Food Res Technol. 2011;233:123-9.

26. Takala TM, Saris PE. A food-grade cloning vector for lactic acid bacteria based on the nisin immunity gene nisl. Appl Microbiol Biotechnol. 2002;59:467-71.

27. Biswas I, Gruss A, Ehrlich SD, Maguin E. High-efficiency gene inactivation and replacement system for Gram-positive bacteria. J Bacteriol. 1993;175:3628-35.

28. Maguin E, Duwat P, Hege T, Ehrlich D, Gruss A. New thermosensitive plasmid for Gram-positive bacteria. J Bacteriol. 1992;174:5633-8.

29. Pomerantsev AP, Sitaraman R, Galloway CR, Kivovich V, Leppla SH. Genome engineering in Bacillus anthracis using Cre recombinase. Infect Immun. 2006;74:682-93.

30. Yao X, Chen T, Shen X, Zhao Y, Wang M, Rao X, Yin S, Wang J, Gong Y, Lu $S$, et al. The chromosomal SezAT toxin-antitoxin system promotes the maintenance of the SsPI-1 pathogenicity island in epidemic Streptococcus suis. Mol Microbiol. 2015:98:243-57.

31. Delorme C, Ehrlich SD, Renault P. Histidine biosynthesis genes in Lactococcus lactis subsp. lactis. J Bacteriol. 1992;174:6571-9.
32. Simoes-Barbosa A, Abreu H, Silva Neto A, Gruss A, Langella P. A foodgrade delivery system for Lactococcus lactis and evaluation of inducible gene expression. Appl Microbiol Biotechnol. 2004;65:61-7.

33. Li R, Takala TM, Qiao M, Xu H, Saris PE. Nisin-selectable food-grade secretion vector for Lactococcus lactis. Biotechnol Lett. 2011;33:797-803.

34. Pan Q, Zhu J, Liu L, Cong Y, Hu F, Li J, Yu X. Functional identification of a putative $\beta$-galactosidase gene in the special lac gene cluster of Lactobacillus acidophilus. Curr Microbiol. 2010;60:172-8.

35. Kok J, Leenhouts K, Haandrikman AJ, Ledeboer AM, Venema G. Nucleotide sequence of the cell wall proteinase gene of Streptococcus cremoris Wg2. Appl Environ Microbiol. 1988;54:231-8.

36. Mierau I, Leij P, van Swam I, Blommestein B, Floris E, Mond J, Smid EJ. Industrial-scale production and purification of a heterologous protein in Lactococcus lactis using the nisin-controlled gene expression system NICE: the case of lysostaphin. Microb Cell Fact. 2005;4:15.

37. Kuipers OP, de Ruyter PG, Kleerebezem M, de Vos WM. Quorum sensing-controlled gene expression in lactic acid bacteria. J Biotechnol. 1998;64:15-21.

38. Guo T, Hu S, Kong J. Functional analysis and randomization of the nisininducible promoter for tuning gene expression in Lactococcus lactis. Curr Microbiol. 2013;66:548-54.

39. Gutiérrez J, Larsen R, Cintas LM, Kok J, Hernández PE. High-level heterologous production and functional expression of the sec-dependent enterocin P from Enterococcus faecium P13 in Lactococcus lactis. Appl Microbiol Biotechnol. 2006;72:41-51.

40. Madsen SM, Arnau J, Vrang A, Givskov M, Israelsen H. Molecular characterization of the $\mathrm{pH}$-inducible and growth phase-dependent promoter P170 of Lactococcus lactis. Mol Microbiol. 1999;32:75-87.

41. Kim EB, Son JS, Zhang QK, Lee NK, Kim SH, Choi JH, Kang SK, Choi YJ. Generation and characterization of thymidine/D-alanine auxotrophic recombinant Lactococcus lactis subsp. lactis IL1403 expressing BmpB. Curr Microbiol. 2010;61:29-36.

42. Sambrook J, Russell DW. Molecular cloning: a laboratory manual. 3rd ed. Cold Spring Harbor: Cold Spring Harbor Laboratory Press; 2001.

43. Holo H, Nes IF. High-frequency transformation, by electroporation, of Lactococcus lactis subsp. cremoris grown with glycine in osmotically stabilized media. Appl Environ Microbiol. 1989;55:3119-23.

\section{Submit your next manuscript to BioMed Central and we will help you at every step:}

- We accept pre-submission inquiries

- Our selector tool helps you to find the most relevant journal

- We provide round the clock customer support

- Convenient online submission

- Thorough peer review

- Inclusion in PubMed and all major indexing services

- Maximum visibility for your research

Submit your manuscript at www.biomedcentral.com/submit
BioMed Central 